\title{
事毒 BeleidsonderzoekOnline
}

Citeerwijze van dit artikel:

Dick Houtman, Stef Aupers en Peter Achterberg, 'Alledaags postmodernisme; De gezagscrisis van de hedendaagse wetenschap', bso 2012, april-juni, DOI:

10.5553/Beleidsonderzoek.000005

DOI: 10.5553/Beleidsonderzoek.000005

\section{Alledaags postmodernisme; De gezagscrisis van de hedendaagse wetenschap}

\section{Dick Houtman, Stef Aupers en Peter Achterberg}

'The "truth" of a theory does not boil down to its reliability but also involves the nature of its selective perspective on the world.'

(Alvin W. Gouldner, 1973: 427)

\section{Inleiding}

'Wetenschap is ook maar een mening', kopte NRC.Next op 14 september 2011 een stelling die treffend samenvat hoe veel Nederlandse burgers tegenwoordig oordelen over wetenschappelijke kennis. Het typisch moderne onderscheid tussen objectieve kennis en morele waarden, feit en fictie, fantasie en werkelijkheid lijkt minder scherp dan voorheen en verschillende surveys laten daarbij zien dat het vertrouwen in wetenschap en technologie de afgelopen decennia daalt, met name in westerse welvarende landen (bijv. Inglehart, 1997). Ook in de Nederlandse politiek lijkt er, tenminste sinds Pim Fortuyn, een zekere onverschilligheid of minachting te bestaan tegenover wetenschappelijke kennis. Politieke ideeën hoefden volgens Fortuyn niet gebaseerd te zijn op de feiten - zij behoefden niet 'waar' of 'rationeel' te zijn, maar moesten vooral fungeren als een soort richtinggevende 'mythen' of 'utopieën' (Pels, 2003: 51-52). In handen van de PVV is Fortuyns fact-free politics inmiddels alleen maar verder uitgewerkt en geperfectioneerd. Zo stelt Wilders (2005: 106) dat ' $[\mathrm{w}] \mathrm{e}$ moeten durven dromen en aldus mogelijk maken wat in Den Haag onmogelijk wordt geacht'.

Wetenschappelijke kennis en harde cijfers over bijvoorbeeld de effectiviteit van straffen, immigratie of criminaliteit in Nederland lijken daarin steeds minder een leidende rol te spelen: feiten worden gerelativeerd, irrelevant geacht of simpelweg ondergeschikt gemaakt aan het politieke ideaal.

In deze bijdrage plaatsen we de gezagscrisis van de hedendaagse wetenschap in cultuur en politiek in een breder, cultuursociologisch perspectief. Het startpunt 
van die analyse is het kennistheoretisch perspectief van de socioloog Max Weber op de complexe relatie tussen waarden en wetenschap - tussen Sollen (hoe men wil dat de wereld is) en Sein (hoe de wereld feitelijk is). Bij het overbrengen van de boodschap dat de sociologie een echte wetenschap is, reduceren de meeste sociologische tekstboeken de ideeën van Weber over de verhouding tussen waarden en wetenschap tot een tandenloos monster. Daarmee wordt helaas onzichtbaar gemaakt dat Webers wetenschapsleer een veelbelovend vertrekpunt biedt voor de analyse van het hedendaagse wantrouwen ten aanzien van wetenschappelijke kennisclaims in cultuur en politiek.

\section{Waarden en wetenschap: een moeilijk huwelijk}

De overtuiging van de naamgever van de sociologie, Auguste Comte, dat een superieur 'wetenschappelijk weten' het 'religieuze geloven' zou kunnen vervangen (Gouldner, 1970: 88-108), dient niet te worden verward met Max Webers ideeën over de 'onttovering van de wereld' en staat hier in feite zelfs lijnrecht tegenover (Houtman, 2008). Weber maakt in zijn godsdienstsociologie immers een systematisch onderscheid tussen religie en magie, met als implicatie dat wetenschap, en dan vooral daarop gebaseerde technologie, wel magie kan vervangen, maar zeker niet religie. Religie is in de optiek van Weber (1963 [1922]: 6), en trouwens ook in die van Durkheim (1965 [1912]: 39-42), immers niet gericht op het realiseren van praktische alledaagse doelen, maar op de toekenning van zin en betekenis aan de wereld en het leven, en dus op het verschaffen van ethische en morele handelingsdoelen. Dit laatste is iets wat de wetenschap onmogelijk kan doen: juist op de allerbelangrijkste levensvragen 'Hoe te leven?', 'Wat te doen?', 'Wat te laten?' - moet zij het antwoord schuldig blijven (Weber, 1948 [1919]: 153).

Weber heeft dan ook geen goed woord over voor wetenschappers die pretenderen een 'objectieve' zin aan de wereld te kunnen toekennen en karakteriseert degenen die geloven dat dit mogelijk is als 'grote kinderen' (Weber, 1948 [1919]: 142). Precies om deze reden kunnen ideeën als die van Marx over 'waar' en 'vals' klassenbewustzijn of die van Durkheim over organische solidariteit als de 'normale' vorm van solidariteit in moderne samenlevingen niet serieus worden genomen: het zijn slechts waardeoordelen, die meer zeggen over de eigen ethische preoccupaties dan over de sociale werkelijkheid. Het zijn misplaatste pogingen om het sociale leven van een 'objectieve' betekenis te voorzien - een betekenis dus, die geen product is van de menselijke geest, maar stevig is gefundeerd in een voorbij de cultuur gesitueerde 'echte' sociale werkelijkheid (Houtman, 2000: 7-12; 2008).

Het vertrekpunt van Webers wetenschapsleer is dan ook de notie van 'waardebetrokkenheid' of 'waardegebondenheid,' volgens welke de verwerving van kennis onontkoombaar plaatsvindt vanuit een relevant geacht gezichtspunt. Zo'n gezichtspunt is wetenschappelijk gezien uiteindelijk arbitrair, in de zin dat het onmogelijk is om 'aan te tonen' dat het superieur is aan enig ander denkbaar gezichtspunt. Natuurlijk zullen onderzoekers het door henzelf gekozen gezichtspunt beter, vruchtbaarder of interessanter vinden dan enig ander, maar een dergelijk 'vinden' dient volgens Webers wetenschapsleer scherp te worden onderscheiden van de vraag of het 'waar' is. Bovendien is een dergelijke 
waardegebondenheid fundamenteler dan de door sociologen meestal op de voorgrond geplaatste doctrine van de waarderingsvrijheid, in de zin dat zij als kennissociologisch feit ten grondslag ligt aan deze aan onderzoekers te stellen morele eis (Zijderveld, 1990: 62-76). Wanneer sociologische kennis niet simpelweg een afspiegeling van de externe sociale werkelijkheid is, maar mede het product van selectie en interpretatie op basis van een waardebetrokken gezichtspunt, dan kunnen onderzoekers op basis van hun onderzoeksresultaten immers niet langer morele of politieke oordelen vellen. Wie dit laatste als onderzoeker wel doet, handelt als de goochelaar die het konijn dat hij eerst onder de oksel heeft gefrommeld, er aan het einde van de voorstelling onder luid applaus van het publiek weer triomfantelijk onder vandaan trekt.

Hoewel sociologen dat slechts zelden onderkennen, reikt de relevantie van Webers wetenschapsleer dus veel verder dan de doctrine van de waarderingsvrijheid. Zoals wij zullen zien, is zijn notie van waardegebondenheid in feite zelfs de quintessens van twee belangrijke theorieën over wantrouwen ten aanzien van wetenschappelijke kennisclaims. Deze theorieën zijn pas tot bloei gekomen sinds de jaren zestig van de vorige eeuw, in nauwe samenhang met het culturele onbehagen en de maatschappelijke turbulentie van destijds - dus niet minder dan grofweg een halve eeuw nadat Weber zijn ideeën over waarden en wetenschap had gepubliceerd.

\section{Historische continuiitteit sinds de jaren zestig}

\section{Moderniteit en cultureel onbehagen}

Net als Karl Marx en Emile Durkheim, de twee andere klassieke grondleggers van de sociologie, heeft ook Max Weber aandacht gevraagd voor de manier waarop processen van modernisering leiden tot cultureel onbehagen over een sociale werkelijkheid waarin mensen zich niet langer 'thuis voelen' (Berger et al., 1973). Onder invloed van rationalisering (onder andere institutionele differentiatie en arbeidsdeling) verliezen traditionele morele en religieuze zingevingskaders volgens de drie grondleggers van de sociologie steeds meer hun greep op moderne samenlevingen en instituties. Moderne instituties worden hierdoor steeds minder ervaren als 'natuurlijk', 'vanzelfsprekend', 'echt' en 'betekenisvol', wat ten koste gaat van hun vermogen om op legitieme wijze voor te schrijven wat goed is en wat slecht, en wat moet worden aangemoedigd of juist belemmerd.

De vroege Durkheim (1951 [1897]), 1964 [1893]) wees op de moderne tendens tot verzwakking van de morele regulering (anomie) en de vroege Marx (1959 [1844]) vroeg aandacht voor het probleem van de vervreemding onder kapitalistische verhoudingen. Webers analyse behelst een generalisering en synthese van beide. Hij benadrukt enerzijds, Marx indachtig, hoezeer processen van rationalisering en bureaucratisering leiden tot het ontstaan van een 'ijzeren kooi', die de menselijke vrijheid in gevaar brengt. Waar hij schrijft over de 'onttovering van de wereld', die er in toenemende mate toe leidt dat 'the world's processes (...) simply “are” and "happen” but no longer signify anything' (Weber, 1978 [1921]: 506), heeft zijn analyse echter ook veel gemeen met die van Durkheim. Het belangrijkste verschil is dat het volgens Weber voor alles de 
wetenschap is die met haar radicaal anti-metafysische ethos de stuwende kracht vormt achter de erosie van stevig gefundeerde zin en moraliteit.

\section{De tegencultuur van de jaren zestig en zeventig}

Het door de grondleggers van de sociologie gethematiseerde culturele onbehagen over de sociale werkelijkheid leidde in de jaren zestig en zeventig tot grote culturele en politieke turbulentie. De bonte verzameling politieke activisten, culturele anarchisten en spirituele zoekers was het destijds immers over één ding eens: de sociale werkelijkheid deugde niet (Zijderveld, 1970). De droom van de Verlichting was ontaard in de nachtmerrie van de technocratie met zijn kille amorele rationaliteit, zijn onpersoonlijke bureaucratische regels en zijn vervreemdende rollen (Roszak, 1969). Men maakte zich over het morele gehalte van 'Het Systeem' weinig illusies, want het staatsapparaat en de grote bedrijven hadden er volgens hen alle belang bij om mensen te laten geloven dat zij gelukkig waren en in een vrije samenleving leefden. Wie wat kritischer was en wat beter keek, ontdekte al snel dat reclame en massamedia zelfs de diepste wensen en verlangens van mensen manipuleerden en dat wat op 'echte' tolerantie leek in feite slechts 'repressieve' tolerantie was. Deze tegenculturele systeemparanoia bereikte een hoogtepunt in het werk van Frankfurter sociologen als Max Horkheimer, Theodor Adorno en Herbert Marcuse, waarin de cultuurindustrie en het consumentisme werden ontmaskerd als manieren om de massa's dom en tevreden te houden en het kapitalisme te vrijwaren van kritiek (Horkheimer \& Adorno, 2002 [1944]; Marcuse, 1964). Op haar beurt werd de wetenschap ontmaskerd als de legitimeringsmachine van het onpersoonlijke, gerationaliseerde beheerssysteem dat door Roszak (1969) in een destijds immens populair boek werd aangeduid als de 'Technocratie'.

Uiteraard bleef in dit klimaat van cultureel onbehagen ook de sociologie zelf niet buiten schot. De 'technocratie' en de instituties van de burgerlijke prestatiemaatschappij (het arbeidsbestel, het onderwijs, maar ook het huwelijk, het gezin en de kerk) hadden ook in de ogen van de jongste generatie sociologen hun vanzelfsprekendheid en geloofwaardigheid verloren. Zij vonden het om die reden problematisch dat ze desondanks in zoveel sociologisch onderzoek nog steeds als 'normaal', 'natuurlijk' en 'onontkoombaar' werden voorgesteld. Er was kortom een discrepantie ontstaan tussen de waardebetrokkenheid van de hoofdstroom van het sociologisch onderzoek enerzijds en de door een nieuwe generatie sociologen omhelsde waarden van vrijheid, emancipatie en persoonlijke authenticiteit anderzijds.

Dit leidde tot een wetenschappelijke gezagscrisis in de sociologie. Op basis van een sterk op Webers wetenschapsleer gelijkende theorie kondigde Alvin Gouldner in The Coming Crisis of Western Sociology (1970) een 'crisis van de sociologie' aan, die reeds volop was losgebarsten op het moment dat het boek verscheen en die tot op de dag van vandaag is blijven voortduren (Horowitz, 1993; Houtman, 2008, 2009; Lopreato \& Crippen, 1999). Deze crisis, zo stelde Gouldner, was simpelweg onvermijdelijk, omdat een discrepantie was gegroeid tussen de 'tegenculturele' waarden van de nieuwe tijdgeest en de waarden die tot op dat moment aan de hoofdstroom van het sociologisch onderzoek ten grondslag lagen. De ideeën van de jonge generatie sociologen over wat 'normaal' 
of 'abnormaal', 'prijzenswaardig' of 'laakbaar' was, waren dusdanig gaan conflicteren met laatstgenoemde, dat de sociologische onderzoeksresultaten niet langer als betrouwbare en neutrale wetenschappelijke kennis werden aanvaard. In plaats daarvan ging men ze beschouwen als een manier om de maatschappelijke status quo te legitimeren door haar te voorzien van een schijn van natuurlijkheid en vanzelfsprekendheid (vergelijk Becker, 1967; Mills, 1963 [1943]).

Sinds de jaren zeventig is deze gedachte dat empirische bewijsvoering niet doorslaggevend is bij de aanvaarding dan wel verwerping van sociologische theorieën uitgegroeid tot een postmoderne kennistheorie. Bekende postmoderne filosofen als Lyotard, Rorty of Toulmin, wijzen - net als de sociologen Weber en Gouldner - op het gegeven dat wetenschappelijke waarheid nooit een afspiegeling van de werkelijkheid is en altijd is verbonden met waarden, macht en belangen. Anders gezegd: wetenschappelijke claims zeggen meer over het gezichtspunt van de onderzoeker dan over de (sociale) werkelijkheid. Het doel is daarmee 'deconstructie': het blootleggen van dit veelal impliciet blijvende gezichtspunt en het demonstreren dat de hierop opgetrokken kennisclaims instorten wanneer het wordt vervangen door een ander, wetenschappelijk gezien even arbitrair gezichtspunt. Volgens een postmoderne socioloog als Seidman (1994: 3) zouden sociologen zelfs 'the false promise of science to achieve objective and universal knowledge' geheel moeten opgeven ten gunste van hun 'role as storytellers or social critics'. Problematisch is wat postmoderne sociologen als Bauman (1987), Seidman (1994) en Lemert (1995) betreft dus niet zozeer dat het werk van sociologen als Marx en Durkheim bol staat van de moralistische uitspraken over wat 'normaal', 'abnormaal', 'vals' of 'pathologisch' zou zijn, maar slechts dat zij deze oordelen voorstellen als 'wetenschappelijk gefundeerd' en 'waar'. Sociale verschijnselen hebben in een postmoderne optiek eenvoudigweg nooit een 'ware' of 'objectieve' betekenis en als zodanig is het onmogelijk om claims hieromtrent, of die nu afkomstig zijn van sociologen of niet-sociologen, voor te stellen als meer of minder 'waar' dan andere.

Wetenschap en politiek zijn vanuit een postmodern perspectief kortom onlosmakelijk met elkaar verbonden, zoals dat dus ook volgens Weber al het geval was; dit gegeven vormt immers de wetenschapstheoretische rationale voor zijn doctrine van de waarderingsvrijheid.

\section{Tegencultuur 2.0: alledaags postmodernisme}

Het hedendaagse culturele en politieke klimaat lijkt in veel opzichten op dat van veertig jaar terug. Natuurlijk kwam destijds de maatschappijkritiek van links en inmiddels van rechts, maar men kan zich afvragen of dit versleten negentiendeeeuwse begrippenpaar nog wel het meest geëigende is voor de analyse van de hedendaagse politiek. De 'linkse' kritiek op kerk en religie van destijds klinkt bijvoorbeeld luid en duidelijk door in de hedendaagse 'rechtse' demonisering van moslims en islam: 'Moslims moeten eigenlijk gewoon net zo progressief worden als wij: ze moeten hun vrouwen meer vrijheid en onze vrouwen meer respect geven, ze moeten onze homo's met rust laten, en ze moeten van onze vrijheid van meningsuiting afblijven' (Houtman, 2008: 28-29; vgl. Duyvendak, 2004; Houtman et al., 2008; Van Bohemen et al., 2011). Natuurlijk waren het destijds vooral hoogopgeleiden die hun pijlen richtten op het establishment, 
terwijl tegenwoordig vooral laagopgeleiden zich roeren (bijv. Van Bohemen et al., 2011), maar toch is de onvrede in de grond van de zaak identiek. Net als destijds omarmt men vandaag de dag meer of minder rebelse noties van vrijheid, ongebondenheid en persoonlijke onafhankelijkheid, stoort men zich aan religieuze en morele bedilzucht, en zegt men regenteske politieke en bureaucratische elites de wacht aan. Provo's als Roel van Duijn en Robert Jasper Grootveld sarden destijds met hun ludieke happenings de Amsterdamse autoriteiten en inmiddels zet Rutger Castricum met behulp van eigentijdse media politici te kakken voor weblog Geenstijl en omroep PowNed.

Ook de electorale aantrekkingskracht van Geert Wilders schuilt voor een belangrijk deel in de manier waarop hij onophoudelijk de gevestigde politiek en het overheidsapparaat op de korrel neemt met redeneringen in de trant van 'zie je wel: het is gewoon een rotzooitje in dit land en dat is de schuld van die zelfgenoegzame linkse elites, die alle machtsposities hebben gemonopoliseerd, elkaar in de vorm van baantjes en subsidies voor linkse hobby's de bal toespelen, en verder de boel gewoon de boel laten'. De hedendaagse samenleving met haar onveiligheid, justitieel proceduralisme en bureaucratische stroperigheid is slecht, moet op de schop en levert nog slechts illustraties van hoe erg het inmiddels geworden is. 'Het moet niet veel gekker worden' - je hoort het Wilders zeggen. Dit culturele en politieke klimaat behelst een soort 'tegencultuur 2.0' en net als destijds gaat het culturele onbehagen over de sociale werkelijkheid hand in hand met wantrouwen ten aanzien van de wetenschap.

Dat wantrouwen valt gedeeltelijk terug te voeren op het ingrijpend veranderde politieke klimaat, waarin links - en dan vooral de PvdA - in de beklaagdenbank is komen te staan (Houtman \& Achterberg, 2009). Dat heeft, net als in de jaren zestig en zeventig, geresulteerd in een waardendiscrepantie tussen de dominante politieke cultuur en een aanzienlijk deel van het (vooral sociaal-

wetenschappelijke) onderzoek. Deze discrepantie manifesteert zich uiteraard bij uitstek in het geval van onderzoek naar bijvoorbeeld stigmatisering, discriminatie en uitsluiting van moslims, naar de wederwaardigheden van multiculturele overheidsinitiatieven, of naar het milieuvraagstuk. Een discussie in de Tweede Kamer tussen Richard de Mos (PVV) en Diederik Samson (PvdA) over de opwarming van de aarde (voor de liefhebbers te vinden op YouTube) biedt een kras voorbeeld van het laatste. Samson legt De Mos een hypothetische situatie voor: 'De heer De Mos is een buschauffeur van een bus met twintig wetenschappers erin. Hij rijdt's nachts op een onverlichte weg de dichte mist in. Negentien van de wetenschappers hebben aan hun modellen afgemeten dat er over 500 meter een scherpe bocht naar rechts volgt. Eén wetenschapper zegt: "Die bocht komt niet, de weg gaat rechtdoor. U kunt gewoon vol gas blijven geven!" Wat doet de heer De Mos op zo'n moment als buschauffeur?' De Mos aarzelt geen moment: 'Ja, de heer De Mos rijdt altijd vrolijk verder.' Het is alsof we weer terug zijn in de jaren zestig en zeventig: men moet zich aan de feiten niet te veel gelegen laten liggen, want de verbeelding moet aan de macht en als de theorie niet strookt met de feiten, dan is dat des te erger voor de feiten.

Het wantrouwen ten aanzien van de wetenschap is vandaag de dag maatschappelijk echter dieper geworteld dan vier decennia geleden. Destijds bestond het postmodernisme zelfs in intellectuele kringen nog nauwelijks, maar 
inmiddels is het doorgedrongen tot in de haarvaten van de samenleving en het alledaagse leven. De overtuiging dat wetenschappelijke kennis altijd eenzijdig en nooit politiek neutraal is, is hiermee een culturele gemeenplaats geworden. In feite is de wetenschap het slachtoffer geworden van haar eigen succes.

Wetenschappelijk onderzoek is de afgelopen decennia immers maatschappelijk gezien steeds meer gewicht in de schaal gaan leggen, of het nu gaat om het bekritiseren of rechtvaardigen van overheidsbeleid of om het verlenen van keurmerken aan personenauto's, voedingsmiddelen of toiletverfrissers. De grote kracht van de wetenschap - de nadruk op de noodzaak van methodische twijfel en op de onmogelijkheid van zekerheid, waarmee zij zich vanouds van religieus en politiek-ideologisch geloof onderscheidt - is hierdoor steeds meer haar achilleshiel geworden.

Veranderingen in het medialandschap als de opkomst van het internet, de introductie van de commerciële televisie en de explosieve toename van het aantal televisiekanalen hebben hieraan een belangrijke bijdrage geleverd. Hierdoor worden immers niet wetenschappelijk geschoolden op dagelijkse basis via televisie, Internet, radio, kranten en tijdschriften geconfronteerd met wetenschappelijke meningsverschillen en tegenstrijdige onderzoeksresultaten: visolie is goed voor het hart, van visolie krijg je kanker; opvoeden doe je met veel begrip en empathie, opvoeden doe je met harde hand en duidelijke regels; geweld in Nederland neemt de afgelopen jaren toe, geweld in Nederland neemt af; we stevenen af op een ecologische catastrofe, het gaat de laatste jaren steeds beter met het klimaat; vaccinaties tegen de Mexicaanse griep zijn noodzakelijk, vaccinaties tegen de Mexicaanse griep zijn overbodig of gevaarlijk. 'Die wetenschappers weten het ook niet en roepen maar wat', zo denken veel niet wetenschappelijk geschoolden vandaag de dag, wanneer zij met dergelijke conflicterende beweringen worden geconfronteerd, zich verder niet bewust van het belang en de onontkoombaarheid van meningsverschillen, kritiek en onzekerheid in de wetenschap. De godsdienstsocioloog Peter Berger (1967) heeft er bijna een halve eeuw geleden al op gewezen: blootstelling aan concurrerende waarheidsclaims leidt gemakkelijk tot een relativering van al die waarheidsclaims.

Wetenschappelijke meningsverschillen worden door de medialogica die wordt gehanteerd bij de selectie van nieuwsfeiten en bij de manier waarop ze worden gepresenteerd, zelfs onvermijdelijk verder uitvergroot en opgeblazen. Niet alle wetenschappelijke bevindingen zijn immers even interessant en er bestaat dan ook een duidelijke voorkeur voor spectaculaire nieuwe onderzoeksresultaten (die per definitie het meest onzeker en het meest omstreden zijn), voor onderzoeksresultaten die een rol (kunnen gaan) spelen in politieke conflicten (waarbij journalisten in de regel meer geïnteresseerd zijn in de politieke implicaties volgens de onderzoeker dan in zijn of haar onderzoeksresultaten zelf), en in meer algemene zin voor onderzoeksresultaten die tot op het bot omstreden zijn. Niets zo goed voor de kijkcijfers als twee klimaatwetenschappers of medische onderzoekers die elkaar in De Wereld Draait Door of Pauw \& Witteman retorisch de hersens inslaan.

\section{Opkomst van alternatieve kennisvormen}


Reeds een halve eeuw terug stelde Johan Goudsblom in zijn proefschrift Nihilisme en cultuur vast dat '[d] e cultuur (...) verzadigd [is] van tegenargumenten' en dat 'de theorie van het "niets is waar" (...) wijd en zijd verspreid [is]' (1960: 218). Dat geldt vandaag de dag dus in nog sterkere mate dan destijds, maar inmiddels wordt tevens duidelijk dat dit nihilistische element in de cultuur gepaard gaat met een zoektocht naar nieuwe waarheden en zekerheden via de constructie van alternatieve postmoderne kennis- en cultuurvormen (Houtman 2008). Daarbij maakt het nihilistische adagium 'niets is waar' steeds meer plaats voor het postmoderne adagium 'in potentie is alles waar'. 'Waren de goden kosmonauten?', zo vraagt Erich von Däniken zich in zijn boek met dezelfde titel af. 'Had Jezus Christus een zoon met Maria Magdalena', zoals Dan Brown in zijn bestseller De Da Vinci Code suggereert? 'Waarom zou dat waar zijn?', vragen wetenschappelijke onderzoekers zich geconfronteerd met dergelijke kennisclaims af. 'Waarom zou dat niet waar zijn?', zo luidt vandaag de dag echter steeds vaker het postmoderne adagium.

Wat ooit als evidente fictie werd beschouwd, wordt thans als reële mogelijkheid overwogen of zelfs als reeds bewezen feit aanvaard. Buiten de gevestigde wetenschappelijke instituties - de universiteiten, onderzoeksinstellingen en laboratoria - komen dan ook alternatieve kennisvormen tot ontwikkeling. Natuurlijk zetten wetenschappers hun nieuwe concurrenten steevast weg als dromers, oplichters of charlatans, maar dat laat onverlet dat hun inzichten door velen worden omarmd, zodat de reguliere wetenschap meer dan in het verleden moet concurreren met alternatieve claims op 'waarheid' en zelfs 'wetenschappelijkheid' (Hammer, 2001).

\section{Holistische spiritualiteit, alternatieve geneeswijzen en complottheorieën}

Zo worden vandaag de dag in westerse landen als Nederland bij de behandeling van ziekte op grote schaal allerlei 'alternatieve' of holistische geneeswijzen toegepast, al dan niet in aanvulling op reguliere medische praktijken: homeopathische middelen, geneeskrachtige kruiden, acupunctuur, voetreflexologie, Reiki, Shiatsu, aromatherapie, hypnotherapie, et cetera (Campbell, 2007). Alleen al in de periode van 1980 tot 1994 is het jaarlijkse bezoek aan alternatieve genezers in Nederland verdubbeld tot 16 procent (Becker et al., 1997), terwijl 40 procent van de bezoekers van alternatieve genezers daar terecht is gekomen uit onvrede over de reguliere geneeskunde (Van Reenen et al., 1997). Dit is geen gerommel in de marge: de alternatieve geestelijke gezondheidszorg is inmiddels ongeveer even groot als de reguliere geestelijke gezondheidszorg voor volwassenen (idem).

Een ander voorbeeld van een alternatieve kennisvorm is het gestaag oprukkende complotdenken (Aupers, 2002, 2012; Knight, 2000; Melley, 2000). Vooral op het internet bekritiseren burgers naar hartelust 'officiële' versies van de waarheid. Ze verzamelen er informatie die ze aanwenden om 'alternatieve' kennis te produceren, die ze vervolgens via webforums of in de vorm van filmpjes via YouTube beschikbaar stellen. Zo treft men op internet volop speculaties aan over de betrokkenheid van de Amerikaanse overheid bij de aanslagen van 9/11; over het duistere spel dat overheid, wetenschap en medische 
industrie speelden bij de vaccinatiecampagne tegen de Mexicaanse griep; en over het malafide samenspel van binnen- en buitenlandse krachten, gericht op de islamisering van Europa - de transformatie van Europa tot Eurabia. Wie de moeite neemt om de feiten eens kritisch tegen het licht te houden, zo luidt de centrale boodschap van deze complottheorieën, die de systeemparanoia van de jaren zestig bijna doen verbleken, kan constateren dat het allemaal nog erger is dan velen al vermoeden.

Het hedendaagse complotdenken blijft niet langer beperkt tot de al eeuwenlang bestaande 'veilige paranoia', waarin het kwaad (de joden, de vrijmetselaars, de communisten) nog aanwijsbaar en lokaliseerbaar was, en dus met een beetje goede wil nog wel buiten de deur te houden. Inmiddels is steeds vaker sprake van 'onveilige paranoia', waarin het kwaad amorf en ongrijpbaar is geworden en zich schuilhoudt in onontwarbare sociale netwerken waarvan zelfs de wetenschap en de eigen overheid deel zijn gaan uitmaken (Knight, 2000). De hedendaagse obsessie voor complotten en samenzweringen doortrekt ook de populaire cultuur, waar verhalen over de betrokkenheid van de Amerikaanse regering bij de moord op Kennedy, films als The Matrix en The Truman Show, tv-series als de $X$-Files en 24 en boeken als Dan Browns The Da Vinci Code op grote belangstelling mogen rekenen (Roeland et al., 2011). Het is wantrouwen en paranoia wat de klok slaat: 'Trust no one' en 'Nothing is what it seems', zoals de $\mathrm{X}$-Files leren.

\section{Dromen over een betere sociale werkelijkheid}

Het wetenschappelijke monopolie op waarheidsvinding ligt dus onder vuur - de feiten worden eerder gezien als probleem dan als oplossing en dat geldt ook voor de alledaagse sociale werkelijkheid. Veertig jaar terug werd het ontsnappen aan zo'n, als vervreemdend ervaren, sociale werkelijkheid een obsessie van de tegencultuur. Lsd-gebruikers, zenboeddhisten en spirituele hippies zochten vrijheid in de diepere lagen van hun bewustzijn en omarmden daarmee hun eigen binnenwereld als ontsnappingsroute uit het 'Systeem'. In dit klimaat werd ook de 'oude' Marx, die van de ontwikkelingswetten van het kapitaal en de onontkoombare socialistische revolutie, vervangen door de 'jonge' Marx, die van de kritiek op het tot vervreemding en onvrijheid leidende kapitalisme. Kleinschalige gemeenschappen en communes in landelijke omgevingen beloofden een ontsnapping uit de anonieme moderne stad en ook de magischmythische werelden van de fantasy fictie (zoals Middle Earth uit Tolkiens Lord of the Rings) oefenden een ongekende aantrekkingskracht uit.

Een vergelijkbaar verlangen naar ontsnapping uit de alledaagse sociale werkelijkheid manifesteert zich ook vandaag de dag, niet het minst in een nostalgisch verlangen naar het lelieblanke en netjes aangeharkte Nederland van weleer - het Nederland van Bromsnor, mijnheer de burgemeester en juffrouw Saartje, waarin de ordelijke gezapigheid slechts werd verstoord door de onschuldige en immer goed geluimde buitenstaander Swiebertje. Maar er is zoveel meer. De cultuurindustrie spuwt aan de lopende band imaginaire fantasiewerelden uit, die gretig aftrek vinden bij het grote publiek. We kunnen in dit verband denken aan Charmed, Buffy the Vampire Slayer, Harry Potter, The Chronicles of Narnia en, uiteraard, Peter Jackson's verfilming van Lord of the 
Rings.

De populariteit van online computer games als Dark Age of Camelot, Everquest en World of Warcraft, allemaal gebaseerd op het fantasy genre, is eveneens een teken aan de wand. Dergelijke spelen zijn al lang niet meer te beschouwen als kinderspelletjes: slechts een kwart van de spelers is onder de 18 jaar en de gemiddelde speelleeftijd is 26 (Yee, 2006). Honderdduizenden Nederlanders spelen inmiddels heroïsche rollen als magiërs, elfen of krijgers in deze interactieve virtuele spelwerelden. $\mathrm{Zij}$ geven daarmee gestalte aan een tweede leven in een andere werkelijkheid en halen hun schouders op wanneer hun wordt gevraagd hoe 'echt' deze 'hyperrealiteiten', zoals de postmoderne Franse socioloog en filosoof Jean Baudrillard (1994 [1981]) ze noemt, eigenlijk zijn. Het kan hen niet zoveel schelen, want aantrekkelijker dan de 'echte' sociale werkelijkheid zijn ze sowieso. 'Gamers have had enough of reality', stelt Jane McGonigal (2011: 2) dan ook vast in haar boek over de populariteit en aantrekkingskracht van computer games. Het is dit culturele onbehagen dat er verantwoordelijk voor lijkt te zijn dat veel Nederlanders in recent onderzoek te kennen geven dat het hen persoonlijk goed gaat, maar dat het met de samenleving juist slecht gaat. De sociale realiteit is voor velen klaarblijkelijk een probleem geworden waaruit men, net als in de jaren zestig en zeventig, wil ontsnappen. Dat zien we terug in de populaire cultuur, de aandacht voor fantasy games, maar ook in de huidige politiek. Wetenschappelijke kennis en feitelijkheden lijken steeds minder richtinggevend in de bepaling van de politieke koers en de voering van het debat. Bij fact-free politics gaat het om een onomwonden keuze voor wat Canovan (1999) de 'redemptieve' in plaats van de 'pragmatische' dimensie van de democratie noemt.

\section{Conclusie: de valorisatieparadox}

De abrupte politieke veranderingen sinds 2002 verklaren slechts een deel van het hedendaagse wantrouwen ten aanzien van de wetenschap in Nederland. De hierdoor gegroeide waardendiscrepantie kan echter slechts van tijdelijke aard zijn, want zodra de grote onderzoeksfinanciers hun probleemdefinities en prioriteiten hebben bijgesteld in lijn met de nieuw waaiende politieke wind, kan het beleidsonderzoek weer probleemloos overgaan tot de orde van de dag. Het vertrouwen in de wetenschap zal daardoor echter niet volledig kunnen herstellen, omdat de onderliggende trend van de postmodernisering van de cultuur onomkeerbaar lijkt. Het is een teken aan de wand dat het vertrouwen in wetenschap, technologie en rationaliteit juist in de wetenschappelijk en technologisch meest ontwikkelde samenlevingen het geringst is (Inglehart, 1997: 79). Deze ontwikkeling voedt enerzijds de overtuiging dat wetenschappelijke kennisclaims altijd en onvermijdelijk eenzijdig en nooit politiek neutraal zijn en stimuleert anderzijds de ontwikkeling van nieuwe en concurrerende kennisvormen om het hierdoor ontstane zingevingsgat op te vullen.

Maar de veralledaagsing van het postmodernisme, het besef dat waarden en wetenschappelijke kennis met elkaar verbonden zijn, wordt mogelijk ook versterkt door het succes en het gezag van de wetenschap zelf. Sinds in 1988 de 'Z' van ZWO ('Zuiver Wetenschappelijk Onderzoek') plaatsmaakte voor de 'N' van NWO ('Nederlandse Organisatie voor Wetenschappelijk Onderzoek') is de 
roep om 'kennisvalorisatie' alleen maar verder toegenomen. Onderzoek moet tegenwoordig vooral maatschappelijk en beleidsrelevant zijn en bij voorkeur gericht op (de oplossing van) actuele sociale problemen. Deze roep om valorisatie onderstreept enerzijds de maatschappelijke waarde van wetenschappelijke kennis, maar indiceert - bezien vanuit het kennistheoretisch perspectief van Weber - een ontwikkeling richting meer waardegebonden onderzoek. Immers: er zijn principieel geen eenduidige en objectieve maatstaven aan te leggen voor wat een relevant sociaal probleem is. Wetenschapsbeoefening raakt zo dan ook steeds meer verbonden met maatschappelijke belangen en politieke conflicten, wat door de ontwikkelingen in de media bovendien steeds zichtbaarder is geworden voor de Nederlandse burger. Dit heeft een paradoxale dynamiek in gang gezet: het maatschappelijke wantrouwen ten aanzien van wetenschap is mogelijk ook de resultante van een groot vertrouwen in wetenschappelijke kennis en het daarmee samenhangende streven naar kennisvalorisatie.

Literatuurlijst

Aupers, S. (2002). 'Everything is Connected': naar een sociologie van paranoia en complottheorieën, Sociologische Gids, 49(3), 313-326.

Aupers, S. (2011). Een verwarrende tijd? Naar een cultuursociologie van nieuwe kennis- en cultuurvormen. In C. Brinkgreve, M. van den Haak, B. van Heerikhuizen, J. Heilbron \& G. Kuipers (red.), Cultuur en ongelijkheid (pp. 212225). Diemen: AMB.

Aupers, S. (2012). 'Trust no one': Modernization, Paranoia and Conspiracy Culture, European Journal of Communication, 27(1) (in press).

Baudrillard, J. (1994 [1981]). Simulacra and Simulation. Ann Arbor: Michigan University Press.

Bauman, Z. (1987). Legislators and Interpreters: On Modernity, Post Modernity, and Intellectuals. Oxford: Polity Press.

Becker, H. (1967). Whose Side Are We On? Social Problems 14(Winter), 239248.

Becker, J.W., De Hart, J., \& Mens, J. (1997). Secularisatie en alternatieve zingeving. Rijswijk: Sociaal en Cultureel Planbureau.

Berger, P. (1967). The Sacred Canopy: Elements of a Sociological Theory of Religion. Garden City: Doubleday.

Berger, P.L., Berger, B., \& Kellner, H. (1973). The Homeless Mind: Modernization and Consciousness. New York: Vintage Books.

Campbell, C. (2007). The Easternization of the West: A Thematic Account of Cultural Change in the Modern Era. Boulder, CO: Paradigm. 
Canovan, M. (1999). Trust the People! Populism and the Two Faces of Democracy. Political Studies, 47, 2-16.

Durkheim, E. (1951 [1897]). Suicide. New York: Free Press.

Durkheim, E. (1964 [1893]). The Division of Labor in Society. New York: Free Press.

Durkheim, E. (1965 [1912]). The Elementary Forms of Religious Life. New York: Free Press.

Duyvendak, J.W. (2004). Een eensgezinde, vooruitstrevende natie: over de mythe van 'de' individualisering en de toekomst van de sociologie, oratie Universiteit van Amsterdam. Amsterdam: Vossiuspers.

Goudsblom, J. (1960). Nihilisme en cultuur. Amsterdam: Arbeiderspers.

Gouldner, A.W. (1970). The Coming Crisis of Western Sociology. London: Heinemann.

Gouldner, A.W. (1973). For Sociology: Renewal and Critique in Sociology Today. London: Allen Lane.

Hammer, O. (2001). Claiming Knowledge: Strategies of Epistemology from Theosophy to the New Age. Leiden: Brill.

Horkheimer, M., \& Adorno, T.W. (2002 [1944]). Dialectic of Enlightenment: Philosophical Fragments. Stanford: Stanford University Press.

Horowitz, I.L. (1993). The Decomposition of Sociology. New York: Oxford University Press.

Houtman, D. (2000). Een blinde vlek voor cultuur: sociologen over cultureel conservatisme, klassen en moderniteit. Assen: Van Gorcum.

Houtman, D. (2008). Op jacht naar de echte werkelijkheid: dromen over authenticiteit in een wereld zonder fundamenten. Amsterdam: Pallas.

Houtman, D. (2009). Een halve eeuw na Moderne Sociologie (1959): J.A.A. van Doorn is dood en de sociologie voelt zich niet zo lekker, Sociologie, 5(4), 521539 .

Houtman, D. (2011a). Counterculture 2.o, lezing Elfde Dag van de Sociologie, 26 mei 2011, Gent.

Houtman, D. (2011b). Culture, Knowledge and Distrust of Scientific Truth Claims: A Cultural-Sociological Analysis, lezing Organization for Economic Cooperation and Development (Trade and Agriculture Directorate), July 4, 2011, Paris. 
Houtman, D., \& Achterberg, P. (2009). Arbeiders en schoolmeesters: een huwelijk in crisis. Socialisme \& Democratie, 66(6), 22-27.

Houtman, D., Achterberg, P., \& Aupers, S. (2011). Feiten, feiten... Wie maalt er nog om feiten? NRC Handelsblad, katern Opinie \& Debat, 9-10 april, 46-47.

Houtman, D., Achterberg, P., \& Duyvendak, J.W. (2008). De verhitte politieke cultuur van een ontzuilde samenleving. In B. Snels \& N. Thijssen (red.), De grote kloof: verhitte politiek in tijden van verwarring (pp. 61-80). Amsterdam: Boom.

Inglehart, R. (1997). Modernization and Postmodernization: Cultural, Economic, and Political Change in 43 Countries. Princeton, NJ: Princeton University Press.

Knight, P. (2000). Conspiracy Culture: From Kennedy to the X Files. London: Routledge.

Lemert, C. (1995). Sociology After the Crisis. Boulder, CO: Westview Press.

Lopreato, J., \& Crippen, T.A. (1999). Crisis in Sociology: The Need for Darwin. New Brunswick, NJ: Transaction.

McGonigal, J. (2011). Reality Is Broken: Why Games Make Us Better and How They Can Change the World. New York: Penguin Press.

Marcuse, H. (1964). One-Dimensional Man. Boston: Beacon Press.

Marx, K. (1959 [1844]). Economic and Philosophic Manuscripts of 1844. Moscow: Progress Publishers.

Melley, T. (2000). Empire of Conspiracy: The Culture of Paranoia in Postwar America. Ithaca, NY: Cornell University Press.

Pels, D. (2003). De geest van Pim: het gedachtegoed van een politieke dandy. Amsterdam: Anthos.

Roeland, J., Aupers, S., \& Houtman, D. (2011). Fantasy, paranoia en het romantisch erfgoed: Max Weber en de geest van de hedendaagse populaire cultuur, Sociologie, 7(1), 3-20.

Roszak, Th. (1969). The Making of a Counter Culture: Reflections on the Technocratic Society and Its Youthful Opposition. New York: Doubleday.

Seidman, S. (1994). Contested Knowledge: Social Theory in the Postmodern Era. Cambridge, MA: Blackwell.

Van Bohemen, S., Kemmers, R., Houtman, D., Aupers, S., \& De Koster, W. (2011). Secular Intolerance in a Post-Christian Society: The Case of Islam in the Netherlands. In D. Houtman, S. Aupers \& W. de Koster (Eds.), Paradoxes of 
Individualization: Social Control and Social Conflict in Contemporary Modernity (pp. 141-156). Aldershot: Ashgate.

Van Reenen, H.-J., Vandermeersch, P., \& Hutschemaekers, G. (1997). Alternatieve GGZ en new age: verslag van een enquête onder alternatieve hulpverleners. Maandblad Geestelijke Gezondheid, 52(12), 1207-1218.

Weber, M. (1948 [1919]). Science as a Vocation. In H.H. Gerth \& C. Wright Mills (Eds.), From Max Weber: Essays in Sociology (pp. 129-156). London: Routledge.

Weber, M. (1963 [1922]). The Sociology of Religion. Boston: Beacon Press.

Weber, M. (1978 [1921]). Economy and Society (Two Volumes). Berkeley/Los Angeles: University of California Press.

Wilders, G. (2005). Kies voor vrijheid: een eerlijk antwoord. Groep Wilders.

Wright Mills, C. (1963 [1943]). The Professional Ideology of the Social Pathologists. In I.L. Horowitz (Ed.), Power, Politics, and People: The Collected Essays of C. Wright Mills (pp. 525-552). New York: Balantine.

Yee, N. (2006). The psychology of Massively Multi-User Online Role-Playing Games: Motivations, emotional investment, relationships and problematic usage. In R. Schreuder \& A. Axelson (Eds.), Avatars at work and play: Collaboration and interaction in shared virtual environments (pp. 168-187). London: Springer-Verlag.

Zijderveld, A.C. (1970). The Abstract Society: A Cultural Analysis of Our Time. New York: Doubleday.

Zijderveld, A.C. (1990). Sociologie als cultuurwetenschap: een beknopte methodologie van de cultuursociologie. Utrecht: Uitgeverij Lemma.

(C) Boom Lemma uitgevers 